\title{
Evading Tactics of Psychological Contract Violations
}

\author{
Huiyuan Mao, Xin Liu \& Hua Ge \\ Shenyang University, Shenyang 110044, China
}

\begin{abstract}
Nowadays, the theory of psychological contract is the focus of human resources research at home and abroad. With the transformation of economic pattern and globalization of world economy, the psychological contract in employment relationship has changed extremely, even has been broken and to be perceived as psychological contract violations. The present article analyzed psychological contract and psychological contract violations, putted forward some evading tactics.
\end{abstract}

Keywords: Psychological contract, Psychological contract violations, Evading tactics

In 1980s, with the development of global economic integration and transformation of economic pattern, enterprises have to materially adjust their management tactic and operation pattern. After a series of innovations such as merger and acquisition, reshuffle, reduction of staff and expenditure, as well as new management methods, etc, the relation between employees and organizations has changed greatly. The employees' former mental balance is broken. In the past, if the employees could work hard and be loyal to their organization, with no doubt, they could permanently work for the organization and develop their career stably there. But now the job guarantee and career stabilization do not exist any more. Caused by the innovation in enterprises, it appeared some issues among employees, such as the playing-down employees' loyalty and satisfaction, the descending work performance, the increasing dissatisfactory and hostile behavior, the rising brain drain rate, and so on. All these problems restrict the development of enterprises. The weight of economic contract in enterprise is descending here, but the weight of psychological contract is going up. The study on psychological contract is widely paid attention to by scholars and enterprises, meanwhile it also has become a hot topic in management field domestically and overseas at present. With the transformation of economic pattern and globalization of world economy, the psychological contract in employment relationship has changed extremely, even has been broken and to be perceived as psychological contract violations. The present article analyzed psychological contract and psychological contract violations, putted forward some evading tactics.

\section{History Root and Development of Psychological Contract}

Argyris was the first person who used the term of psychological contract to depict the interactive relation between the employees and their foremen in 1960s. In 1962, Levinson deemed the psychological contract as an unwritten contract and a summation of expectations from organization and employees. Psychological contract here emphasized on the inherent, recessive, never expressive expectations, which existed before forming the relation of employers and employees. Of the expectations, some were specific, and some were inexplicit. In 1965, Schein defined Psychological Contract as "......in organizations, there exists a set of inexplicit expectations among each member, different supervisor as well as the others". And he also pointed out that psychological contract had two administrative levels. They were individual psychological contract and organization psychological contract. In 1973, Kotter considered that psychological contract was an inner agreement between individuals and organizations. It concretized the cost paid out by one side and redound received by the other side. In the late 1980s, the understanding about the concept deepened more. American scholar Rousseau believed that psychological contract was an understanding or a faith on employees' and employers' compulsoriness. On the basis of promises, trust and perception, psychological contract formed with the background of employment relationship. In 1994, Robinson, Kraatz and Rousseau pointed out again that psychological contract substantially was parties' subjective faith and a process constructed in practice, that is, “employees' promises, understanding and apperceive on exchange relation of external \& internal contribution (effort, loyalty, etc) as well as organization inducement (reward, promotion, etc)". In 1997, Herriot and Pemberton thought psychological contract was a perception about various responsibilities that employers and employees should provide for one another in employment relation. This perception came from apperceive towards the formal agreement or kept in different expectations.

As has been said above, there is not a monolithic definition of psychological contract yet. But there is one point of common understanding, that is, psychological contract is a recessive contract for coordinating the relation between employees and organizations. It is the basis of harmonious employment relation. Based on the promises, the essential characteristic of this concept is the subjective apperceive for the obligation and compulsory of one another. 


\section{Characteristics of Psychological Contract}

\subsection{Subjectivity}

The contents of psychological contract is employees' cognizance or subjective perceive in terms of their own obligation and organization's obligation, but not the obligation itself. Due to the employees' unique experiences and opinions on the relation between themselves and organization, psychological contract maybe differ from the economic contract as well as the understanding and explanation of the others or the third side (organization agent). Different employees identify and breach psychological contract in different ways. It presents subjectivity.

\subsection{Dynamics}

The formal economic contract is stable. With the variance of work notion, the growth of the organization, and the development of employees' needs, psychological contract is in a changing and emendatory state. Any changes on organization operation mode could influence the production of psychological contract. No matter the change is physical or social. The longer employees work in the organizations, the wider their psychological contract contains, the more latent content on expectations and responsibilities in the relation of employees and their organization has. (Baud·Machin, 2000)

\subsection{Informality and Implicitness}

In economic life, apart from the formal, open and dominant economic contract with obvious legal and regulative effects, there is another kind of important contract. It does not form by letters and written expression, but by various tacit and complicated agreements between employees and their organizations. Psychological contract has no definite promises as economic contract, but it influences people's economic behavior deeply.

\subsection{Bi-directionality and Non-equivalence}

Psychological contract is bidirectional. But the expectations and promises between employees and organizations in psychological contract do not correspond one by one. The confidence and loyalty that the employees have toward their enterprises can not be weighed. Organizations' promises and employees' expectations and contributions are also incapable to be corresponded.

\subsection{Incentive Function}

Schein (1980) has ever pointed out, "Psychological contract is powerful determinant of behavior in organizations, though it is with no clear written statement". If psychological contract was breached, employees would reappraise and reconstruct more contracts in organizations.

\subsection{Adaptability}

Psychological contract has no fixed pattern and uniform standard. Just as the fact that effective incentive methods and countermeasures could not take effect in any circumstances in organizations, content of psychological contract is adjusting and changing along with organizations' development in different periods and employees' extending apperceive on psychological contract. There is no unchangeable psychological contract.

\section{Psychological Contract Violation}

Modern society is characterized by diversification. The change, destruction and violation of psychological contract are unavoidable. If employees thought that they had fulfilled enterprises' demands but enterprises had not undertaken their responsibilities as employees expected, psychological contract violation would appear. Many research scholars find that employees usually do not consider what they get less than enterprises promise them as psychological contract violation. To illustrate the definition of psychological contract violation, Morrison and Robinson (1997) defined it as a subjective experience, that is to say, when enterprises met employees' psychological contract except one or several demands, employees would subjectively perceive psychological contract violation.

Western scholars have done some investigations on the extent of psychological contract violation. Robinson and Rousseau (1994) found that about 55 per cent of MBA students had experienced psychological contract violation in the first two years of their working life. Otherwise when psychological contract was destructed, employees might think over the exchange relation with enterprises, and the employment relationship might change. However, Turnley and Feldman (1999) discovered that only $25 \%$ of employees had experienced psychological contract violation. The difference was caused by different formation of psychological contract and measurement. Strictly speaking, most of employees has experienced psychological contract violation. In an investigation on over 800 administrators, Turnley (1996) found 81 per cent of respondents had thought enterprises did not meet at least one of what they promised them. Nevertheless, only 24 per cent of respondents believed what they got was less than what enterprises promised them. Examining the fulfillment extent of psychological contract mainly depends on measurement of psychological contract violation. 


\section{Evading tactics of Psychological Contract Violation}

\subsection{Evading “ideology misunderstanding”, enterprises should construct human-oriented enterprise culture.}

Enterprise culture is the microcosmic foundation formed by employees' collective psychological characteristics, mental outlook and administrative mode. In the process of development, enterprises' administrators usually only pay attention to the tangible economic contract, but ignore the intangible psychological contract. They even seldom consider employees' feeling and expectation. This necessarily will lead to employees' psychological contract violation and it will undoubtedly reduce enterprises' benefits. Enterprises should construct human-oriented enterprise culture, putting talents to full use and efficient use. They should effectively develop employees' ability and potentiality. In order to figure a powerful spiritual support for their employees, enterprises should also create an atmosphere and a spirit which are strenuous, enterprising, harmonious, equal and just. This will assuredly create a good environment and space for reaching and maintaining psychological contract. And it could arouse employees' enthusiasm for putting their shoulders to the wheel, and adhere to "promises" which has been accepted by enterprises and employees in the "contact". Accordingly it will form a harmonious employment relationship and realize the enterprises' strategic target.

\subsection{Evading “perception misunderstanding”, enterprises should set up a good communication mechanism.}

The psychological contract between enterprises and employees possesses dynamic character. It is continuously changing and modifying. If merely depending on perceptive promises to each other, the two sides will produce mutual dissatisfaction and inconsistent pace. Finally it will lead to psychological contract violation and break the steady employment relationship established between enterprises and employees. Only if the two parts set up an all-round dynamic communication and intercommunication channel can they understand demands and desires of each other. Enterprises should periodically and irregularly communicate with their employees, regard the growth of employees, assist employees to design their perfect future profession, and create opportunities for employees to exert their independent innovation consciousness and independent participation consciousness.

\subsection{Evading "growth misunderstanding”, enterprises should build effective training and promotion mechanism.}

Nowadays, in labor market supply exceeds demand. Under the circumstance, employees are in quite passive position. At this time, if employees perceive psychological contract violation and that enterprises are reluctant to or do not take any compensation measures, the effect of negative behavior caused by employees will be obvious, and even could affect the image and the benefit of enterprises. By providing with effective training, advanced study and promotion mechanism, enterprises can not only lessen employees' psychological contract violation, but also increase their satisfaction. The fact that enterprises give opportunities of training and advanced study to their employees means what employees have done is recognized or appreciated by enterprises. They have potentialities to be promoted. Promotion will bring some active changes such as work contents, management right, and salary. The most important is to enhance employees' sense of identity and belonging.

\subsection{Evading “obligation misunderstanding”, enterprises should pay attention to promote employees 'work satisfactions.}

If employees thought that they had fulfilled enterprises' demands but enterprises had not undertaken their responsibilities as employees expected, psychological contract violation would appear. Thus enterprises must pay attention to promote employees' work satisfactions to lessen or eliminate the psychological contract violation. Employees' satisfactions are determined by how their demands have been met. When working in enterprises, employees usually have some demands. For instance, they hope that they could obtain suited reward, do a challenging job, win recognition, and opportunities of advanced study and promotion. They also want to work in a harmonious atmosphere and a comfortable environment, and expect a bright future.

\subsection{Evading “participation misunderstanding”, enterprises and employees should strengthen mutual trust.}

Trust is the core of psychological contract. It directly influences the behaviors of enterprises and employees. The employees' trust in enterprises plays an important role in subjective experiences of psychological contract violation. It affects employees' acknowledgement and explanation on psychological contract violation, as well as the resulted behaviors (Robinson, 1996). When employees perceive that enterprises destroy psychological contract, psychological contract violation will appear. Employees will spontaneously believe that enterprises' words and deeds are inconsistent. If they consider that their present work will not obtain affirmatory return, their work motivation will decrease (Robinson, 1996). Enterprises should break employees' former executive or obedient role, and increase employees' participation. They should make employees know enterprises' goal very well, and give employees voice right in the process of decision-making and implement. And thereby enterprises could enhance employees' sense of achievement and pride. Enterprises should respect suggestions from employees and try to foster employees' identity sense. This may relieve employees' uncertainty on the future of enterprises. This may also form an open and straight-out atmosphere so that to buildup trust between enterprises and employees. The mutual trust is the important link of forming and maintaining a good psychological contract. 


\section{References}

Argyris, c. (1960).Understanding organizational behavior. Homewood, IL: The Dorsey Press.

Rousseau, G.M. (1989). Psychological and Implied Contracts in Organizations. Employee Responsibilities and Right Journal, 2(2):121-139

Morrison, E. W., \& Robinson, S. L. (1997).when employees feel betrayed: A model of how psychological contract violation develops. Academy of Management Review, 22, 226-256.

Robinson, S.L, \& Rousseau, D.M (1994).violating the psychological contract: Not the exception but the norm. Journal of Organizational Behavior, 15, 245-259.

Turnley, W.H., \& Feldman, D.C.(1999).A discrepancy model of psychological contract violations. Human Resource Management Review, vol 9.

Guzzo, R.A. \& Noonan, K.A. (1994). Human Resource Practices as communication in the psychological contract. Human Resource Management, 33, 447-462. 